report the use of intravenous magnesium sulphate in two cases of severe tetanus at our centre.

Case report Case 1. A 1-year-old unimmunised Indonesian boy presented with one week history of lethargy and reduced oral intake with multiple episodes arching of back and limbs stiffness. We achieved good spasm control with intravenous Magnesium Sulphate, Diazepam, Phenytoin and oral Baclofen. He was asymptomatic upon discharge, with no neurological deficit. Both patients received intramuscular Tetanus Toxoid and Tetanus Immunoglobulin.

Case 2. A 2-year-old unimmunised Burmese-Indonesian girl presented with 3 days history of neck stiffness, trismus, abdominal rigidity and opisthotonus position. She had no autonomic dysfunction. She required intravenous (IV) infusion of Magnesium Sulphate, and high doses of IV Midazolam, Diazepam, Baclofen and Chlorpromazine to control her spasm. She underwent tracheostomy after 30 days of mechanical ventilation. She was spasm free after 39 days of treatment and all medications were gradually weaned off. She was discharged home after 83 days of admission with tracheostomy but with no neurological deficit. Both patients did not develop any autonomic dysfunction and magnesium toxicity.

Conclusion The use of intravenous Magnesium sulphate infusion was proven to be beneficial in achieving muscle spasm control in both patients, sparing the use of paralyzing agent and mechanical ventilation in one of the patients. However, monitoring for magnesium toxicity remains a challenge.

\section{P579 TWO CASES OF HYPOTHALAMIC HAMARTOMA: CORRELATION BETWEEN CLINICAL MANIFESTATIONS AND IMAGING FEATURES}

'Elena Demidenko*, ${ }^{1}$ Olga Ribalko, ${ }^{1}$ Nikolay Kaladze, ${ }^{2}$ Svetlana Dmitryuk, ${ }^{2}$ Oleg Nikolaenko, ${ }^{1}$ Valentina Divinskaya. ${ }^{1}$ V.I.Vernadsky Crimean Federal University Medical Academy Named after S.I.Georgievsky, Simferopol, Russian Federation; ${ }^{2}$ Crimean Republic Children Hospital, Simferopol, Russian Federation

10.1136/archdischild-2019-epa.913

Hypothalamic hamartomas are rare neuronal migration anomalies (incidence 1-2 per 100000 newborn). These benign malformations are morphologically divided into sessile and pedunculated.

Over the past 2 years in our clinic two patients with both morphological forms were diagnosed by using MR imaging.

We report the case of a newborn, who presented with moderate seizures in NICU department. MRI was performed to asses severity of brain damage due to assumed HIE. Sessile hypothalamic hamartoma $1 \mathrm{~cm}$ in diameter was an incidental finding. Patient also had a minor intraventricular hemorrhage. On follow-up examination in a year hamartoma increased in size, however its relative size to the brain was the same. Few episodes of seizures (with gelastic component) were noted during the first year of life. No evidence of precocious growth.

A 12-year-old girl presented with signs of precocious puberty. Routine MR imaging of the brain showed large pedunculated hamartoma instead of assumed pituitary microadenoma. Neurological signs, seizures are absent.

According to these cases, clinical phenotypes and morphological types of hamartomas are highly correlated. Accurate prognosis and proper treatment can be provided for the patients with similar forms of malformations.

\section{P580 PARENTS PERSPECTIVE ON INTRODUCING NASO- GASTRIC TUBE FEEDING AT HOME FOR BABIES WITH BRONCHIOLITIS}

Desha Wasala*, Jamie Campbell, Jemma Virtue. Bristol Royal Hopsital for Children, Bristol, UK

\subsection{6/archdischild-2019-epa.914}

Introduction Telephone interviews with parents were conducted as part of a hospital-wide, multi-professional pilot project to introduce naso-gastric tube (NGT) feeding at home for babies with feeding difficulties due to bronchiolitis, with the aims of improving parent experience, shortening length of stay in hospital and empowering parents to participate in their child's care.

Method We identified 42 patients who met our inclusion criteria of being admitted to hospital for NGT feeding due to bronchiolitis from September 2017 - March 2018. A survey letter to parents explained the project intentions, reason for the interviews and an option to opt out.

The interview comprised 5 closed questions, followed by open questions to explore the answers. Questions were targeted at understanding ideas, concerns and expectations of the proposed project, with respect to parents' previous hospital experience.

Key response themes Overall response to the project was positive, with the concept of NGT feeding at home being welcomed by most interviewees. Reasons included being able to care for baby in a relaxed environment with less disruption to daily routine, feeling empowered and reduced risk of exposure to other infections in hospital. 18 interviewees said they would take up the offer to be NGT trained in order to increase the likelihood of early discharge from hospital, provided sufficient training was provided. Negative reasoning included their baby being too young, being first time parents, or previous bad experiences with their baby pulling out the NGT or being very unwell with bronchiolitis.

Parents' mains concerns revolved around points of contact outside weekday hours, especially for accessing trouble-shooting advice (e.g. NGT blockage/dislodgement). Interviewees were asked for views on how they could feel comfortable and supported at home, with the main themes including 24-hour contact (including a pathway for trouble-shooting) and written material. The proposition of training packs to be given as part of the service, covering these matters, was welcomed.

All parents were happy to have a member of the community nursing team contact them and/or visit them at home to give advice and support in managing NGT feeds at home.

Outcome These responses were shared at the final multi-professional meeting for the project, which included representatives of hospital management. This contributed to approval and progression of the pilot project which ran from October 2018 to March 2019.

\section{P581 THE IMPACT OF HAVING PAEDIATRIC CLOSE OBSERVATION BEDS: A CROSS-SECTIONAL STUDY}

Beatrice Nguyen*, Raymond Chin, Setthy Ung, John Whitehall. Western Sydney University, Medical School, Sydney, Australia

10.1136/archdischild-2019-epa.915

Objective To determine the importance of Paediatric Close Observational Beds (COBs) in the treatment of sick children 